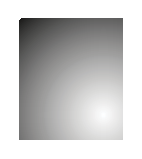

\title{
As Interfaces entre Empreendedorismo Social, Negócios Socials e Redes Socials no Campo Social
}

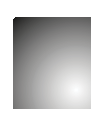

\author{
The Interfaces Between Social Entrepreneurship, Social \\ Businesses and Social Networks in the Social Field
}

Maria de Fátima da Silva

Faculdade Paulista de Serviço Social. Barra Funda, SP, Brasil.E-mail: mfatimasillva@gmail.com

Laysce Rocha de Moura

Instituto Federal de Educação, Ciência e Tecnologia do Rio Grande do Norte (FRN). Natal, RS, Brasil. E-mail: laysce.moura@ifrn.edu.br

Luciano Antonio Prates Junqueira

Programa de Estudos Pós-Graduados em Administração. Higienópolis, SP, Brasil. E-mail: junq@pucsp.br

\section{Resumo}

Este ensaio discute os conceitos do empreendedorismo social, dos negócios sociais e das redes sociais no enfrentamento das demandas sociais, respondendo à pergunta: há interfaces entre esses conceitos? A busca pela mudança social tem no empreendedorismo social, nos negócios sociais e nas redes sociais a possibilidade de gerar ações inovadoras por organizações que atuam tanto no setor público como no privado, com o objetivo de promover a transformação social. As interfaces podem contribuir para a construção do campo da gestão social na medida em que a ação empreendedora no desenvolvimento dos negócios sociais intensifica-se com as redes sociais. O debate dessas ideias sugere a abertura de novos caminhos que possam contribuir para o enfrentamento dos problemas sociais.

Palavras-chave: Empreendedorismo Social. Negócios Sociais. Redes Sociais.

\section{Abstract}

This essay discusses the concepts of social entrepreneurship, social businesses and social networks in responding to social demands, answering the question, there interfaces between these concepts? The pursuit for social change has on social entrepreneurship, social businesses and social networks the ability to generate innovative actions by organizations working in both the public and private sectors, in order to promote social transformation. Interfaces can contribute to building the field of social management to the extent that the entrepreneurial action in the development of corporate business intensifies with social networks. The discussion of these ideas suggests opening up new paths that can contribute to coping social problems.

Keywords: Social Entrepreneurship. Social Business. Social Networking. 


\section{INTRODUÇÃO}

A variedade dos problemas sociais nos tempos atuais exigem esforços na busca de soluções. Vencer a pobreza não significa criar nichos de mercado que insiram os cidadãos nas práticas de consumo, mas sim, criar condições para a emancipação e o desenvolvimento humano. Analisar isoladamente o PIB como um indicador da riqueza de um país não é suficiente sem considerar um contexto social amplo. Faz-se necessário acompanhar o desenvolvimento e a evolução econômica, considerando as necessidades de investimentos no ser humano (como cuidados com sua educação, formação, saúde, lazer e cultura), isto é, criar políticas sociais que atendam as demandas da população, permitindo o acesso dos mais carentes que se encontram à margem da sociedade.

Nessa perspectiva de análise, as relações estão caminhando para uma nova configuração, em que os limites de atuação da esfera pública ou privada já não estão bem delimitados. Assim, novos tipos organizacionais estão surgindo e, para tanto, novas formas de conhecimento e gestão também estão sendo requeridos para que se consiga resolver os problemas sociais.

Essa nova realidade que está sendo construída estabelece uma nova relação entre Estado e sociedade, entre público e privado. Até período recente, o Estado era o promotor exclusivo das políticas sociais, mas essa situação começou a mudar em função das demandas e das pressões advindas de pessoas e grupos organizados, até mesmo dos organismos governamentais que buscam novas formas de gestão, novas maneiras de atender às necessidades sociais. (JUNQUEIRA, 2006, p. 198)

Diante disso, abre-se uma nova perspectiva no enfrentamento dos problemas sociais, seja pelo empreendedorismo social ou por outras formas que assumam as organizações da sociedade civil. Esse campo demanda não só uma ação inovadora, mas também a reconfiguração dos papéis dos diversos atores sociais sejam eles, as próprias organizações, o Estado e a iniciativa privada. Da relação em rede emerge um novo campo de atuação qual seja o de negócios sociais, um campo em construção e, como tal, apoia-se em diferentes influências conceituais para lidar com uma realidade complexa e desafiadora dos aspectos sociais e ambientais. (DIAS; CREMONEZZI; CAVALARI, 2013)

Segundo Comini (2012), na literatura encontram-se três perspectivas que explicam os negócios sociais. A perspectiva europeia, nascida da tradição de economia social (associativismo e cooperativismo), enfatiza a atuação de organizações da sociedade civil com funções públicas. A perspectiva norte-americana privilegia as organizações privadas com lógica de mercado, mas se dedica às soluções dos problemas sociais. E a terceira, predominante em países em desenvolvimento, enfatiza iniciativas de mercado que visam à redução da pobreza e transformação das condições sociais dos indivíduos marginalizados ou excluídos.

Para Dias, Cremonezzi e Cavalari (2013), os negócios sociais são como organizações que atuam com a lógica de mercado, semelhante a perspectiva americana, entretanto em sua missão o objetivo é agregar valor e transformação social. Portanto, visam propiciar impactos sociais agregando valor à sociedade $e$ aliando retorno financeiro para sua manutenção $e$ sustentabilidade. As redes sociais estão ocupando um papel relevante como meio de viabilizar os negócios sociais, favorecendo o seu processo de consolidação.

As redes sociais são geradas pela própria sociedade e pelos atores que dela fazem parte, na medida em que canalizam esforços na consecução do desenvolvimento local e da gestão social. Além de assumirem papel importante na gestão das políticas sociais, pois intensificam a articulação entre os atores (BERTOLINO et al., 2013). Uns dos mobilizadores desse processo são os empreendedores sociais que combinam a paixão presente na missão social com disciplina, inovação $e$ determinação nos negócios sociais.

O empreendedorismo social, com os conhecimentos existentes no seu âmbito, vem ampliando as discussões de um modelo de economia de mercado social em que a meta do mercado e do lucro tem sido buscada conjuntamente com a de coesão social por meio de diferentes tipos de políticas de bem-estar social para alavancar o processo da mudança social. (MARTINELLI, 2009)

Diante dessa realidade, fenômenos antigos e novos ganham novas perspectivas, e este ensaio discute os conceitos do empreendedorismo social, negócios sociais e das redes sociais no enfrentamento 
das demandas sociais, respondendo À pergunta: há interfaces entre esses conceitos? As interfaces podem contribuir para a reflexão do campo da gestão social? Assim, vão emergindo novas perguntas. Dessa forma, inicia-se a análise dos conceitos de empreendedorismo social, negócios sociais e redes sociais na tentativa de melhor entender a articulação entre eles.

\section{Empreendedorismo Social}

Nas últimas décadas, as organizações têm buscado novas formas de atuar com foco no impacto social. É nesse contexto que emergem as discussões sobre empreendedorismo social. Segundo Dees (2001), esse fenômeno não é novo, pois antes da utilização do termo já havia iniciativas que poderiam se enquadrar como empreendedorismo social. A utilização do termo e o aumento de empreendimentos sociais se tornaram foco de diversos estudos, em face das organizações que atuam no segmento social buscarem a sustentabilidade financeira.

De uma forma mais restrita, o termo está associado justamente às iniciativas empreendidas por organizações sem fins lucrativos. Porém, há um entendimento mais amplo que não restringe o foco apenas a essas organizações, mas também para empresas $e$ organizações públicas (AUSTIN; STEVENSON; WEI-SKILLERN, 2006). Além disso, Dees (2001) evidencia algumas abordagens de outros autores tais como Say (criação de valor), Schumpeter (inovação e agente de mudança), Drucker (oportunidades) e Stevenson (desempenho), que abordaram o tema de empreendedorismo no âmbito econômico.

Já na perspectiva social, é possível compreender o Empreendedorismo Social como um

[...] conceito que representa uma variedade de atividades e processos para criar e sustentar valor social, utilizando abordagens empreendedoras e inovadoras e constrangidas pelo ambiente externo. (BROUARD; LARIVET, 2011, p. 50 tradução nossa)

Entretanto, Austin, Stevenson e Wei-Skillern (2006, p. 2 tradução nossa) são mais objetivos e afirmam: "Nós definimos empreendedorismo social como atividades inovadoras e criadoras de valor que tanto podem ocorrer em organizações sem fins lucrativos, empresas ou setor governamental". Dees (2001) também coaduna com a ideia que empreendedorismo social pode estar presente em qualquer organização e afirma que "[...] empreendedores sociais são uma espécie no gênero dos empreendedores, com uma missão social" (DEES, 2001, p. 2 tradução nossa). O Canadian Center Social Entrepreneurship corrobora com as definições de Austin, Stevenson e Wei-Skillern (2006) e Dees (2001) que discute o conceito de empreendedor social como

Indivíduos que são "Líderes no campo da
mudança social, e podem estar presente em or-
ganizações do setor privado, público e sem fins
lucrativos". Esses inovadores sociais combinam
um espírito empreendedor, com a preocupação
do "social", bem como a sustentabilidade eco-
nômica, reconhecendo que o ponto central, são
as comunidades, como um fator crítico para a
sustentação do crescimento econômico e do
desenvolvimento. (CCSE, 2001, p. 8 tradução
nossa)

Entretanto, segundo Dees (2001, p. 4 tradução nossa), os empreendedores sociais desempenham o papel de agente de mudanças do setor social, por:

- Adotar uma missão para criar e sustentar valor social (não apenas valor privado),

- Reconhecer e buscar implacavelmente novas oportunidades para servir essa missão,

- Envolver-se em um processo de contínua inovação, adaptação e aprendizagem,

- Agir com ousadia sem estar limitado por recursos disponíveis em mão, e

- Expor a responsabilização elevada a eleitorados servidos e para os resultados criados.

Dessa forma, o conceito tem como referência o ator que toma a frente do processo, ou seja, o empreendedor social para viabilizar o empreendimento social. (DEES, 2001)

Brouard e Larivet (2011, p. 45 tradução nossa) conceituam os empreendedores sociais

[...] como quaisquer pessoas que com seu espírito empreendedor e personalidade irão atuar como agentes de mudança e líderes para resolver os problemas sociais por meio do reconhecimento de novas oportunidades e encon- 
trar soluções inovadoras, e estão preocupados com a criação de valor social mais do que com valor financeiro.

Para Martinelli (2009, p. 209), o contexto "[...] sociocultural e político-institucional no qual o empreendedorismo surge e se desenvolve, o empreendedor é um inovador que combina e transforma os fatores de produção (trabalho, terra e capital, além de conhecimento e capital social)".

Corroborando com essa perspectiva que o contexto sociocultural influencia o empreendedor, para Correa e Vale (2013, p. 78) "[...] o desempenho do empreendedor é influenciado ou condicionado pela natureza das suas redes de imersão social, [...] e por seus atributos pessoais". Assim, o contexto social impacta a ação empreendedora.

Em Der moderne Kapitalismus (1916-27), Sombart (apud BROUARD; LARIVET, 2011) observa que a criatividade e a capacidade de romper padrões $e$ valores tradicionais que caracterizam o empreendedor capitalista podem ser encontradas em todos os povos, grupos sociais, mas são mais frequentes em membros de determinadas minorias. Corroborando com essa visão do empreendimento de determinados grupos sociais, Martinelli (2009, p. 227), ao abordar o empreendedorismo étnico, identifica que "[...] as características sociais e culturais do grupo étnico são relacionadas à estrutura de oportunidade disponível, na qual os empreendedores precisam encontrar possibilidades para abrir um negócio, mantê-lo e expandi-lo".

Portanto, a criação de valor se configura como ponto central do empreendedorismo social, por meio de iniciativas inovadoras que buscam promover mudança social e, assim, compreender que os empreendedores sociais são os atores do empreendedorismo social. Diante disso, os empreendedores sociais desenvolvem modelos organizacionais na busca de novas formas de atuação a partir das empresas sociais e/ou negócios sociais as quais se definem como

\footnotetext{
Empresas sociais - organizações que exercem missões ou propósitos sociais que operam para criar benefício à comunidade, independentemente de propriedade ou estrutura jurídica $e$ com diferentes graus de autossuficiência financeira e inovação social. (BROUARD; LARIVET, 2011, p. 39 tradução nossa)
}

Nessa mesma direção, os autores demonstram que há uma afinidade teórica entre os termos empreendedor social e o empreendedorismo social a partir do levantamento realizado em estudos acadêmicos de 1991 quando foi escrita a primeira definição até o ano de 2010. (BROUARD; LARIVET, 2011)

Para Brouard e Larivet (2011), o conceito de empreendedor social incorpora o conceito de empreendedorismo social. Segundo os autores, a empresa social pode existir independentemente dos outros dois conceitos. Essa discussão é explicitada por eles na Figura 1, em que os traços contínuos representam relações teóricas mais fortes, representados pelas linhas 1a, 1b, 2a e 4a (empreendedor social, empreendedorismo social com a empresa social), enquanto os tracejados são relações de fraca intensidade linhas $2 b$ e $3 a$ (empresa social para o empreendedor social e o empreendedorismo social), isto é, os autores apontam que a empresa social pode ser criada por um empreendedor social, mas a gestão pode ser feita por um gestor, que não necessariamente é um empreendedor social. Em síntese, observa-se que por meio das empresas sociais se viabilizam os negócios sociais na busca de agregar valor social e benefício à comunidade.

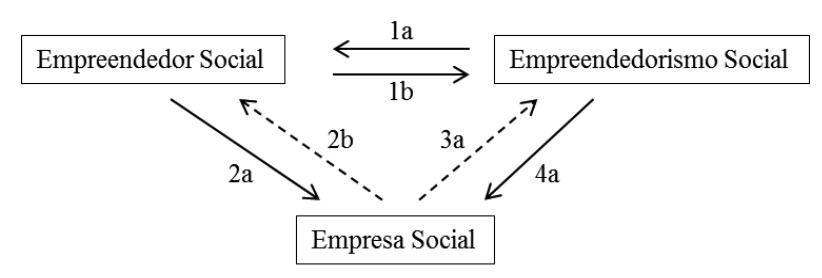

Figura 1: Relacionamento Teórico entre os Conceitos Fonte: Brouard e Larivet (2011, p. 51)

Assim, é possível entender que devido ao crescimento dos problemas e das necessidades sociais na maior parte do mundo, espera-se que o empreendedorismo social continue a crescer como prática e em importância (DEES, 2001; CHRISTIE; HONIG, 2006). Nessa perspectiva, o empreendedorismo social pode viabilizar novos negócios sociais que permitam o enfrentamento das demandas sociais.

\section{Negócios Socials}

A análise dos problemas sociais exige esforços para a busca de soluções na intervenção da realidade social. 
As novas tecnologias e o aumento das trocas entre mercados, bem como a frustração com ações governamentais e de organizações estatais no atendimento às questões sociais ampliam a criação de novos formatos de negócios na busca de soluções. (MOREIRA; URRIOLAGOITIA, 2011; ZAHRA et al., 2008; BULL, 2008)

Especialmente nos países em desenvolvimento, esforços na busca de soluções são ainda maiores, e exigem a elaboração de propostas inovadoras dada à multiplicidade e a extensão dos problemas sociais. Da mesma forma, também são analisados meios para a construção do desenvolvimento econômico desses países.

Segundo Junqueira (2004), as organizações da sociedade civil e os novos modelos de negócios sociais se constituem como alternativas privilegiadas para fazer frente aos problemas sociais que afetam o conjunto da população, diante das dificuldades do setor público no enfrentamento dos problemas sociais.

Prahalad (2005), em seus estudos, defende a ideia de que as estratégias de negócios bem formuladas e executadas podem contribuir para a erradicação da pobreza. No entanto, reconhecer que a desigualdade é um dos fatores que influenciam a pobreza é um importante passo para sua erradicação. Sem, em entrevista a Setti (2012), refere-se que o desenvolvimento econômico de um país compreende a melhoria da qualidade de vida que se leva e às liberdades que se desfruta. Desse modo, para Henriques (2003, p. 65), "[...] redistribuir a renda e a riqueza no Brasil emerge como elemento central para erradicar a pobreza, contribuir para a dinâmica do crescimento econômico e criar as bases sólidas para o desenvolvimento sustentado e solidário".

Esse contexto de busca por melhorias sociais favorece o aparecimento de novos modelos de negócios para atender tais demandas sociais. Os chamados negócios sociais que estão em desenvolvimento, os quais buscam criar soluções de mercado que possam contribuir com o processo de construção de soluções para superação de alguns dos problemas sociais $e$ ambientais de forma autossustentável. (DIAS; CREMONEZI; CAVALARI, 2013)

Esse novo modelo de negócios possibilita compreender que o lucro não é um fim em si mesmo, mas um meio para gerar soluções que ajudem a reduzir a pobreza, a desigualdade social e a degradação ambiental.
Para Yunus (2010), o conceito de negócio social tem em sua essência o desafio de suprir lacunas e resolver problemas sociais e ambientais com sustentabilidade financeira e eficiência, as quais se constituem como um novo tipo de negócio no mundo do capitalismo.

Já Comini, Barki e Aguiar (2012) colaboram para o debate ao indicarem três termos, empresas sociais, negócios inclusivos e negócios sociais, que constituem:

[...] alguns dos termos frequentemente utilizados para explicar organizações com intenção de resolver problemas sociais, com sustentabilidade financeira e eficiência ao utilizar mecanismos de mercado. (COMINI; BARKI; AGUIAR, 2012, p. 386)

Esse campo de negócios sociais é algo recente e em desenvolvimento, portanto, os conceitos atuais são apresentados com visões distintas por diversos autores, como Yunus (2010), por exemplo. Comini, Barki e Aguiar (2012) identificam que coexistem termos, conceitos e definições diferentes que, por vezes, dificultam a interlocução entre os diversos atores interessados em desenvolver novos negócios ou investir nesse mercado. Ao se analisar o conceito de negócio social cabe refletir sobre o processo de gestão social, que de algum modo alinha-se ao de negócios sociais.

Para Gondin, Fischer e Melo (2006), a gestão social se sustenta na busca pelo bem-estar, representando um avanço em relação à gestão tradicional e tecnocrática, pois sua racionalidade apoia-se não apenas em interesses econômicos, mas em interesses sociais e do bem comum. Boullosa e Schommer (2008) corroboram com essa visão, para quem a gestão social como processo é vista como um modelo de gestão voltado ao social na busca por solução dos problemas sociais locais, levando em consideração as tensões e conflitos locais.

Assim, "[...] promove a integração dos recursos disponíveis em prol de uma coletividade quase sempre pouco ativa e articulada". (BOULLOSA; SCHOMMER, 2008, p. 7)

Dessa forma, o campo de estudo dos negócios sociais nos remete a visão da sociologia econômica contemporânea que traz o conceito de redes dentro dos mercados, onde estes são compreendidos como resultado de interações sociais profundas e com formas específicas que não necessariamente depende de pre- 
missas estritamente dedutivas (ABRAMOVAY, 2004). Nesse contexto, a interação social se estabelece a partir da intervenção e atuação das organizações sociais. Os diferentes atores devem ser analisados e compreendidos em suas diferentes posições, considerando que as instituições remetem a ideia de que estão imersas nas estruturas sociais, regulam e normatizam as ações individuais.

Essa discussão das interações sociais entre os diversos atores possibilita a identificação de novos modelos de gestão dos negócios sociais. A demanda que se coloca nesse campo é de como o empreendimento social se torna produtivo e sustentável financeiramente, atingindo seus objetivos e promovendo seu valor social. Nesse contexto, os negócios sociais mediados pelas redes sociais constituem um meio de identificar novos os empreendimentos sociais.

\section{Redes Socials}

A sociedade civil contemporânea tende cada vez mais a organizar-se por meio das redes sociais. No âmbito das Ciências Sociais, as redes sociais emergem do resultado das interações entre indivíduos, grupos e/ ou organizações. (JUNQUEIRA, 2008)

As raízes das redes sociais vêm de diversas perspectivas teóricas, como da sociometria concebida por J. L. Moreno (1934) para quem os grupos são representados graficamente como uma coleção de pontos conectados por linhas para identificar os relacionamentos em forma de rede entre pessoas e seus padrões de interação. (CARRINGTON; SCOTT, 2011)

Nesse sentido, Junqueira (2000, p. 40) define as redes sociais como "[...] um conjunto de pessoas e organizações que se relacionam para responder às demandas e às necessidades da população de maneira integrada, respeitando o saber e a autonomia de cada membro". Já para Marteleto (2001, p. 72) representam "[...] um conjunto de participantes autônomos, unindo ideias e recursos em torno de valores e interesses compartilhados".

Nos estudos realizados por Granovetter (2000) evidencia-se a perspectiva sociológica de que as redes integram os atores em seus contextos relacionais $e$ possibilitam o acesso a oportunidades existentes na estrutura social e econômica. Assim, Granovetter et al., (1998, p. 219 grifos dos autores) as define como um

[...] conjunto de nós ou atores (pessoas ou organizações) ligados por relações sociais ou laços de tipos específicos. Um laço ou relação entre dois autores tem força [strength] e conteúdo. O conteúdo inclui informação, conselho ou amizade, interesses compartilhados ou pertencimentos e, tipicamente, algum nível de confiança.

Dessa forma, emerge a discussão de como as redes sociais podem ser constituídas como ação estratégica do e para o empreendimento social (JUNQUEIRA, 2006). Assim, as redes sociais podem se constituir como uma das estratégias subjacentes utilizadas pela sociedade no compartilhamento da informação e do conhecimento mediante as relações entre atores que as integram.

Assim, as redes sociais possibilitam um crescimento orgânico, no qual os atores locais lideram o processo de expansão e adaptação ao seu contexto. Além de constituírem como uma resposta potencial para lidar com os desafios sociais no enfretamento das desigualdades sociais. Nesse sentido, as redes sociais desempenham um papel importante na articulação do poder e na busca do compromisso com as mudanças.

Dessa forma, esse processo descentraliza a necessidade de investimento de capital e cada um dos empreendedores locais mobilizam uma comunidade e recursos para distribuir informações, produtos e serviços. Entretanto, as redes sociais também representam uma alternativa à necessidade de uma gestão social.

Nesse contexto, Putnam (1993) aborda a confiança, a cooperação e a reciprocidade como características que facilitam a solução de problemas da ação coletiva nas redes sociais.

Essas características se aplicam as redes que não podem ser mantidas por meio de autoridade, pois são geradas pela própria sociedade, canalizando esforços na consecução do desenvolvimento local. Também assumem papel importante na gestão das políticas sociais porque intensificam a articulação entre os atores.

Assim, o processo de redes, ao articular os diversos atores sociais, públicos, estatais e privados $e$ mesmo lucrativos, possibilita superar a incapacidade dos responsáveis pela gestão dos microprocessos das políticas sociais. 
"Enquanto o Estado descentraliza seu poder, possibilita a criação de novos formatos organizacionais, que constituem uma resposta da sociedade civil às demandas de alguns de seus segmentos" (JUNQUEIRA, 2004, p. 30). Com as redes sociais essas organizações e os diversos atores sociais são articulados, viabilizando a participação e a democratização da tomada de decisão na gestão das políticas sociais. A rede como uma realidade social pode também criar conhecimentos que lhes são próprios, numa perspectiva intersetorial e que resulta das relações internas e externas às organizações.

As parcerias são formas de trabalhar cada vez mais utilizadas pelas organizações, quer sejam públicas, privadas ou sem fins lucrativos, com o fim de em conjunto atingirem objetivos comuns. No entanto, são necessários esforços e competências de diversos atores para o enfrentamento das demandas.

Além disso, há uma crise em relação à legitimidade das instituições políticas no que se refere à representatividade dos anseios da sociedade na medida em que há uma maior conscientização da população em relação aos seus direitos. Dessa forma, as parcerias seriam um caminho encontrado para a construção de políticas públicas e projetos sociais para essas problemáticas.

A ampliação das demandas quanto à cidadania, a crise de legitimidade das instituições políticas tradicionais, novas relações entre as esferas do mercado e da sociedade e a noção de risco $e$ urgência no equacionamento de problemas sociais são alguns dos fatores que estão por detrás de transformações nas esferas do Estado, da sociedade civil e do mercado que levariam à construção de parcerias nas políticas sociais. (TEODOSIO; ALVES; ARRUDA, 2010, p. 2)

Outro aspecto é a existência de novas relações entre Estado, mercado e a sociedade. Isto se reflete no estreitamento das ligações em que há uma participação mais estreita da sociedade na formulação, implementação e avaliação das políticas públicas e dos projetos sociais, bem como das empresas no âmbito social. Portanto, a relação que antes era caracterizada pelo conflito passou a ser mais dialogada.

Interações entre atores de Estado, organizações da sociedade civil e empresas adquiriram lugar de destaque nas discussões acadêmicas e na formulação de agendas de políticas so- ciais a partir das últimas décadas. No passado, as dinâmicas de relacionamento entre atores de Estado, movimentos sociais e corporações caracterizaram-se pela dominância de uma lógica de embate, conflito, controle recíproco e busca de responsabilização pelos problemas sociais. Nas últimas décadas, assiste-se a uma proliferação de diferentes formas de articulação entre esses atores, muitas delas balizadas por tentativas de construção de políticas, programas e projetos sociais sob diferentes graus e formas de colaboração. (TEODÓSIO, 2010, p. 16)

Essas articulações recebem inúmeras denominações tanto no meio acadêmico como no senso comum, "configurando como uma verdadeira polissemia" (TEODÓSIO, 2008, p. 16). Elas são conhecidas como parceria, aliança, cooperação, aliança estratégica intersetorial, colaboração intersetorial, coalizão, intersetorialidade, complementaridade, contratação, terceirização ou Cross-sector Social-oriented Partnerships (CSSPs). (TENÓRIO, 2000; FISCHER; BOSE; MENDONÇA, 2003; SELSKY; PARKER, 2005; JUNQUEIRA, 2008; TEODÓSIO, 2008)

O fenômeno não é novo, mas sua intensificação ocorreu no início do século XXI, quando o crescimento do terceiro setor também estava em evidência. Austin (2001, p. 17) tem uma visão bem otimista e afirma que "[...] o século XXI será a era das alianças". Ele entende as alianças como "novas formas de trabalhar em conjunto no sentido de atingir seus objetivos $e$ contribuir para a sociedade". (AUSTIN, 2001, p. 17)

A intensificação e ampliação das parcerias, tendo em vista o alcance de objetivos em comum e a busca da resolução de problemas complexos para atender as demandas sociais deu origem a um emaranhado de relações que podem ser vistas ou entendidas metaforicamente como uma rede. A rede social é composta de diversos atores que buscam coletivamente solucionar problemas que afetam a sociedade.

Nas redes, os objetivos definidos coletivamente articulam pessoas e instituições que se comprometem a superar, de maneira integrada, os problemas sociais. Essas redes são construídas entre seres sociais autônomos, os quais compartilham objetivos que orientam sua ação, respeitando a autonomia e as diferenças de cada membro. Daí a importância de que cada organização pública, estatal ou privada, desenvolva seu saber para colocá-lo, de modo integrado, 
a serviço do interesse coletivo. (JUNQUEIRA, 2008, p. 207 grifo dos autores)

Nesse sentido, é possível destacar dois aspectos, que se pressupõe que sejam características intrínsecas das redes, são: a de construção coletiva e autonomia dos atores. Essas características remetem a questões organizacionais que exigem uma nova postura das instituições envolvidas. As redes sociais, a priori, são caracterizadas por relações horizontais de poder, em que todos os entes possuem autonomia, preservando suas identidades e no compartilhamento da ação.

As redes empoderam seus participantes, pois elas vivem do fluxo das relações. Em um território, muitos atores podem articular-se em rede, mobilizadas por visões e objetivos compartilhados, para transformar situações. Redes acolhem entes autônomos, com suas identidades peculiares, para, em um relacionamento horizontal, realizarem ações com parceria, articulando múltiplos saberes, experiências e poderes, os quais tornam o conjunto mais apto para lidar com os complexos problemas apresentados à gestão social. (INOJOSA; JUNQUEIRA, 2008, p. 178)

Assim, com esse processo é possível agregar diversas pessoas e organizações que possuem conhecimentos, competências e habilidades, na construção de parcerias na perspectiva das redes, possibilitando o enfrentamento dos problemas sociais complexos, bem como o seu entendimento. Nessa perspectiva, a interface entre redes sociais, negócios sociais e empreendedorismo social viabiliza-se pela mediação das redes a partir das interações sociais presentes tanto nos negócios sociais como nos empreendimentos alavancados pelos novos empreendedores sociais.

\section{Sobre As Interfaces}

Ao longo dos últimos anos, o tema relacionado ao enfrentamento das questões sociais tem estado presente em diferentes agendas de pesquisadores, sociedade civil organizada e governo. Corroborando com a reflexão dessas questões, delinearam-se conceitos que contribuem no enfrentamento dos problemas sociais.
Destaca-se que a busca pela mudança social tem no empreendedorismo social, nos negócios sociais e nas redes sociais a possibilidade de gerar ações inovadoras por organizações que atuam tanto no setor público como privado, com o objetivo de promover a transformação social.

A criação de valor se configura como ponto central do empreendedorismo social que se caracterizam em atividades e processos que promovem a inovação social. Nesse sentido, o empreendedor social é relevante para a emergência do negócio social, identificando oportunidades e soluções para os problemas sociais. A sua atuação pode acelerar o processo de mudanças, além de inspirar outros atores a se engajarem em uma causa comum.

$\mathrm{Na}$ medida em que as redes sociais $e$ as parcerias são constituídas, há a possibilidade de aumentar a amplitude da transformação social, pois a interação social torna possível compartilhar conhecimentos, experiências e recursos no processo de gerar uma teia social que viabiliza laços de solidariedade e troca. A autonomia dos atores nas suas decisões, tomadas de forma coletiva e horizontal, possibilitam a democratização no enfrentamento das demandas sociais.

As interfaces do empreendedorismo social, dos negócios sociais e das redes sociais podem contribuir para a construção do campo da gestão social. A ação empreendedora no desenvolvimento dos negócios sociais intensifica-se com as redes sociais. Os conceitos discutidos abrangem o campo da gestão social no sentido de atingir objetivos sociais definidos coletivamente que permitem buscar uma sociedade justa, equânime e sustentável.

Apesar da existência de outras dimensões não consideradas nesta análise, com ela pretendeu-se dar início a uma reflexão de um processo ainda em construção mediante a compreensão da interface desses conceitos que possibilita intervir na realidade social de maneira intersetorial.

O debate dessas ideias sugere a abertura de novos caminhos que possam contribuir não só para o campo da gestão social como também levantar questionamentos que provoquem inovações sociais no enfrentamento dos problemas sociais. 


\section{REFERÊNCIAS}

AUSTIN, J.; STEVENSON, H.; WEI-SKILLERN, J. Social and Commercial Entrepreneurship: Same, Different, or Both? Entrepreneurship Theory and Practice, Texas, USA, v. 30, n. 1, p. 1-22, 2006.

Parcerias: fundamentos e benefícios para o terceiro setor. São Paulo: Futura, 2001.

ABRAMOVAY, R. Entre Deus e o diabo: mercados e interação humana nas ciências sociais. Tempo Social - Revista de

Sociologia da USP, São Paulo, v. 16, n. 2, 2004.

BERTOLINO, C. S. P. et al. Gestão Social, Redes sociais e a Produção Acadêmica: visita aos Anais dos EnAPGs de 2004 a 2012. ENANPAD XXXVIII, Rio de Janeiro, 2013. Anais... Rio de Janeiro, 2013.

BOULLOSA, R.; SCHOMMER, P. C. Limites da natureza da inovação ou qual o futuro da gestão social? In: ENCONTRO DA ASSOCIAÇÃO NACIONAL DE PÓS-GRADUAÇÃO E PESQUISA EM ADMINISTRAÇÃO, 32, 2008, Rio de Janeiro. Anais... Rio de Janeiro: ANPAD, 2008. p. 7.

BROUARD, F; LARIVET, S. Essay of Clarifications and Definitions of the Related Concepts of Social Enterprise, Social Entrepreneur and Social Entrepreneurship. In: FAYOLLE; A.; MATLAY, H. (Ed.). Handbook of Research on Social Entrepreneurship. Cheltenham: Edward Elgar, 2011. p. 29-56.

CARRINGTON, J. P.; SCOTT, J. The Sage handbook of Social Network Analysis: Sage Publications: Los Angeles/London/New Delhi/Singapore/Washington DC, 2011. p. 1-8.

CCSE. Social entrepreneurship, Discussion Paper n. 1, Canadian Center for Social Entrepreneurship (CCSE), February, 8, 2001.

COMINI, G.; BARKI, E.; AGUIAR, L.T. A three-pronged approach to social business: a Brazilian multi-case analysis social businesses. Revista de Administração, São Paulo, v. 47, n. 3. p. 385-397, 2012.

Negócio social: um novo conceito ou um novo rótulo? [2014]. Disponível em: < http://brasil.nextbillion. net/blog/2011/04/13/negcio-social-um-novoconceito-ouum-novo-rotulo>. Acesso em: 13 mar. 2014.
CREMONEZZI, P. B. Negócios sociais: estudo de caso sobre fundo de investimento de impacto no Brasil. 2012. 76p. Dissertação (Graduação em Gestão Ambiental) Escola de Artes, Ciências e Humanidades, Universidade de São Paulo, São Paulo.

DEES, J. G. The meaning of social entrepreneurship.

\section{Center for the Advancement of Social}

Entrepreneurship. Fuqua School of Business, Duke University, Durham, 2001. Disponível em: <www.fuqua. duke.edu/centers/case/documents/dees_SE.pdf $>$. Acesso em: 10 nov. 2014.

DIAS, S.; CREMONEZZI, P. B.; CAVALARI, D. C. Territórios em movimento: caminhos e descaminhos da gestão social e ambiental. In: VII Encontro Nacional de Pesquisadores em Gestão Social, Belém, 2013. Anais... Belém/PA: ANPAD, 2013.

FISCHER, R. M.; BOSE, M.; MENDONÇA, L. R. Desafios da atuação social através de alianças intersetoriais. São Paulo: Seminários de Administração FEA/USP, 2003.

\section{GRANOVETTER, M. A theoretical agenda for} economic sociology. [2000]. Disponível em: <https:// escholarship.org/uc/item/4mk4g08q\#page-4>. Acesso em: 11 nov. 2013.

GRANOVETTER, M. CASTILLA, E.; HWANG, H. Social Networks in Silicon Valley. In: LEE, C. M. et al. (Ed.).

The Silicon Valley Edge: a habitat for innovation and entrepreneurship. Stanford: Stanford University Press, 1998. p. 218-247.

GONDIM, S.; FISCHER, T. M. D.; MELO, V. P. Formação em gestão social: um olhar crítico sobre a experiência de pós-graduação. In: ENCONTRO DA ASSOCIAÇÃO NACIONAL DE PÓS-GRADUAÇÃO E PESQUISA E ADMINISTRAÇÃO, Salvador, Brasil, 23-27 set. Anais... Salvador: ANPAD, 2006. p. 1-16.

HENRIQUES, R. Desnaturalizar a desigualdade e erradicar a pobreza no Brasil. In: NOLETO, Marlova Jovchelovitch; WERTHEIN, Jorge (Org.). Brasil, pobreza e desigualdade no Brasil: traçando caminhos para a inclusão social. Brasília, DF: UNESCO, 2003.

INOJOSA, R. M.; JUNQUEIRA, L. A. P. Práticas e saberes: desafios e inovações em gestão social. Organização \& Sociedade, Salvador: UFBA, v. 15, n. 45, p. 171-180, abr.-jun. 2008. 
JUNQUEIRA, L. A. P. A Gestão social: organizações parceria e redes sociais. In: CANÇADO, A. C. et al.

Os desafios da formação em gestão social. Palmas, TO: Coleção Enanpegs, 2008.

Organizações sem fins lucrativos e redes sociais na gestão das políticas sociais. In: CAVALCANTI, M. (Org.). Gestão social, estratégias e parcerias: redescobrindo a essência da administração para o terceiro setor. São Paulo: Saraiva, 2006. v. 1, p. 195-218.

A gestão intersetorial das políticas sociais e o terceiro setor. Saúde e Sociedade, São Paulo, v. 13, n. 1, p. 25-36, jan.-abr. 2004.

Intersetorialidade, transetorialidade e redes sociais na saúde. Revista de Administração Pública, Rio de Janeiro, FGV, v. 34, n. 6, p. 35-45, nov.-dez. 2000.

. Descentralização, intersetorialidade e rede como estratégias de gestão da cidade. Revista FEA-PUC-SP, São Paulo, v. 1, p. 57-72, nov. 1999.

MARTELETO, R. M. Análise de redes sociais: aplicação nos estudos de transferência da informação. Ciência da Informação, Brasília, DF, v. 30, n. 1, p. 71-81, jan.-abr. 2001.

MARTINELLI, A. O contexto do empreendedorismo. In: MARTES, A. C. B. (Org.) Redes e sociologia econômica. São Carlos, SP: Edufscar, 2009.

MOREIRA, P.; URRIOLAGOITIA, L. El emprendimiento social. Revista Española del Tercer Sector, Madrid, v. 17, p. 17-40, enero-abril, 2011.

PUTNAM, R. D. The Prosperous community: social capital and public life. American Prospect, Princeton, New Jersey, USA. v. 13, p. 35-42, 1993.

PRAHALAD, C. K. The Fortune at the bottom of the pyramid. Upper Saddle River, NJ: Wharton School Publishing. 2005.

SETTI, Ricardo. Entrevista com o Nobel de Economia Amartya Sen: ele fala sobre China, Índia, Brasil - e diz que a crise na Europa se resolve com ênfase no crescimento. Revista VEJA, São Paulo, maio 2012. Coluna Ricardo Setti. Disponível em: <http://veja.abril. com.br/blog/ricardo-setti/tag/amartya-sen/> . Acesso em: 15 out. 2014.
TENÓRIO, F. G. Aliança e parceria: uma estratégia em Alves \& Cia. Revista de Administração Pública, Rio de Janeiro: FGV, v. 34, n. 3, p. 35-52, maio-jun. 2000.

TEODÓSIO, A. S. S. Parcerias tri-setoriais: em busca de seus desdobramentos sobre a cidadania na América Latina. Trabalho de Conclusão de Curso (Tese). Escola de Administração de Empresas de São Paulo da Fundação Getulio Vargas, Universidade de São Paulo (FGV-EAESP), São Paulo, 2008.

TEODÓSIO, A. S. S.; AlVES, M. A.; ARRUDA, M. C. C. Parcerias tri-setoriais em políticas públicas: possibilidades e armadilhas em três experiências brasileiras. In: XXXIV Encontro da Associação Nacional de Pós-Graduação e Pesquisa e Administração, Rio de Janeiro. Anais... Rio de Janeiro: ANPAD, 2010.

\section{YUNUS, M. Criando um negócio social: como}

iniciativas economicamente viáveis podem solucionar os grandes problemas da Sociedade. Rio de Janeiro:

Elsevier, 2010. 